\title{
Clinical significance of transmembrane 4 superfamily in colon cancer
}

\author{
H Hashida', ${ }^{1,5}$ A Takabayashi ${ }^{2}$, T Tokuhara', N Hattori', T Taki', H Hasegawa ${ }^{3}$, S Satoh ${ }^{5}$, N Kobayashi ${ }^{4}$, \\ Y Yamaoka ${ }^{5}$ and M Miyake*,
}

'Department V of Oncology and Department of Thoracic Surgery, Kitano Hospital, Tazuke Kofukai Medical Research Institute, 2-4-20, Ohgimachi, Kita-ku, Osaka 530-8480, Japan; ' Department of Surgery, Kitano Hospital, Tazuke Kofukai Medical Research Institute, 2-4-20, Ohgimachi, Kita-ku, Osaka, 530-8480, Japan; ${ }^{3}$ First Department of Internal Medicine, Ehime University School of Medicine, Oazashizukawa, Shigenobu-cho, Onsen-gun, Ehime 791-0295, Japan; ${ }^{4}$ First Department of Surgery, Ehime University School of Medicine, Oazashizukawa, Shigenobu-cho, Onsen-gun, Ehime 7910295, Japan; ${ }^{5}$ Department of Gastroenterological Surgery, Kyoto University Graduate School of Medicine, 54, Shogoin Kawahara-cho, Sakyo-ku, Kyoto 606-8507, Japan

Cell motility is an important cellular function closely related to the processes of tumour progression and metastasis. Several members of transmembrane 4 superfamily (TM4SF) have been reported to be associated with cell motility and metastatic potential of solid tumour. The aim of this study is to clarify the clinical significance of the member of TM4SF (MRP-I/CD9, KAII/CD82 and CDI 5 I) in human colon cancer. We studied 146 colon cancer patients who underwent curative surgery and studied the expression of MRP-I/ CD9, KAII/CD82 and CDI 5 I using reverse transcriptase - polymerase chain reaction and immunohistochemistry. We found that 64 patients (43.8\%) had MRP-I/CD9-positive tumours and that the overall survival rate of patients with MRP-I/CD9-positive tumours was much higher than that of patients with MRP-I/CD9-negative tumours (89.8 vs 50.8\%, P<0.00I). In contrast, 63 patients (43.2\%) had KAl//CD82-positive tumours and the overall survival rate of patients with KAll/CD82-positive tumours was also higher than that of patients with KAl//CD82-negative tumours (84.8 vs 54.9\%, $P=0.002$ ). On the other hand, positive CD/5/ expression had a bad effect on the overall survival rate of patients with colon cancer ( 61.2 vs $74.9 \%, P=0.022$ ). In a multivariate analysis, MRP- I/CD9 status was a good indicator of the overall survival $(P=0.007)$. We have shown that the reduction of MRP-I/CD9 and KAII/CD82 expression, and the increasing CDI5I expression are indicators for a poor prognosis in patients with colon cancer. This is a first report describing about the relation between $\mathrm{CDI} 5 \mathrm{I}$ and colon cancer.

British Journal of Cancer (2003) 89, 158-167. doi:10.1038/sj.bjc.66010I5 www.bjcancer.com

(c) 2003 Cancer Research UK

Keywords: TM4SF; MRP-I/CD9; KAII/CD82; CDI5I; colon cancer

Cell motility plays an important key function related to the process of tumour progression and metastasis (Miyake and Hakomori, 1991). It is partially dependent on adhesion molecules and proteases (Hashida et al, 2001, 2002a). Previously, we reported that the motility-related protein-1 (MRP-1) is an antigen recognised by monoclonal antibody (MAb) M31-15 which inhibits cell motility and the MRP-1 sequence coincides with the cluster of differentiation antigen 9 (CD9) (Miyake et al, 1991). In our previous reports, we showed MRP-1/CD9-overexpressing tumour cells negative cell motility and metastatic potential (Ikeyama et al, 1993). Therefore, MRP-1/CD9 regulates cell motility and is a receptor for negative signal ligands. In addition, negative MRP-1/ CD9 expression was associated with a poor prognosis in breast cancer (Miyake et al, 1996), lung cancer (Higashiyama et al, 1995) and pancreatic cancer (Sho et al, 1998). These data also suggest that MRP-1/CD9 expression might be associated with metastatic ability and degree of malignancy. MRP-1/CD9 belongs to the transmembrane 4 superfamily (TM4SF), which is characterised by four transmembrane domains delimiting two extracellular regions

*Correspondence: Dr M Miyake; E-mail: miyakem@kitano-hp.or.jp. Received 18 October 2002; revised 12 March 2003; accepted 23 March 2003 of unequal size, as well as a particular fold in the large extracellular loop (Wright and Tomlinson, 1994).

KAI1/CD82 is also a member of TM4SF. KAI1/CD82 expression suppressed experimental metastasis of rat prostate tumour cells (Dong et al, 1995), and decreased motility and invasion of colon carcinoma cells (Takaoka et al, 1998). KAI1/CD82 is considered to be a metastasis-suppressor gene of prostate cancer and low KAI1/ CD82 expression has been reported to be involved in the malignant progression of prostate cancer (Dong et al, 1996). We also showed that decreased KAI1/CD82 gene expression was an indicator of poor prognosis in lung cancer (Adachi et al, 1996), breast cancer (Huang et al, 1998) and pancreatic cancer (Sho et al, 1998). These data show that KAI1/CD82 is an important tumour suppressor gene in cancer metastasis and progression.

On the other hand, CD151 is also a transmembrane molecule that has been characterised as a member of the evolutionally conserved TM4SF, and it is known as SFA-1 and PETA-3 (Fitter et al, 1995; Hasegawa et al, 1996). CD151 cDNA shows an open reading frame of 253 amino acids that encodes a protein of molecular mass $28 \mathrm{kDa}$. In addition, human CD151 gene locates on chromosome 11p15.1. CD151 in involved in cell adhesion, cell motility, metastasis, and stability and formation of hemidesmosomes (Yauch et al, 1998). 
Several members of TM4SF are associated with the metastatic phenotype. In addition, for the most part, they work negatively. Recently, it was reported to be the first member of the TM4SF to show signs of being a positive effecter of metastasis (Testa et al, 1999). Moreover, CD151 enhances cell motility and cancer metastasis (Kohno et al, 2002) and CD151 overexpression leads to a poor prognosis of the patients with non-small cell lung cancer (Tokuhara et al, 2001). Therefore, CD151 is a metastasis-associated antigen that appears to contribute to the metastatic phenotype positively. These findings set $C D 151$ apart from $M R P-1 / C D 9$ and $K A I 1 / C D 82$ that appear to act as metastasis-suppressor genes. It may contribute to the collapse of tetraspanin/tetraspanin complexes. In addition, no consistent findings have been reported as a prognostic indicator for CD151 gene in colon cancer. As part of our evaluation of members of the TM4SF as possible prognostic predictors, we performed a retrospective study on the expression of the $M R P-1 / C D 9$ gene, the recently identified KAI1/CD82 gene and the CD151 gene in human colon cancer.

\section{MATERIALS AND METHODS}

\section{Clinical characteristics of the patients}

We studied 146 patients with up to stage III colon cancer who had undergone surgery at the Department of Surgery of the Kitano Hospital between October 1994 and May 2001. All patients underwent curative surgery. The postsurgical staging of each tumour was classified according to the tumour-node-metastasis (TNM) staging system (Sobin and Wittekind, 1997). The clinical characteristics of the patients are presented in Table 1. In all, 84 of patients were men and 62 were women. The median age of the patients was 62.8 years, with a range of $35-80$ years. The patients could be broken down into 25 with pathological stage I, 46 with stage II and 75 with stage III disease. The mean follow-up period for all patients was 44.3 months, with a range of 6.3-85.9 months.

\section{Tumour specimens}

One-half of each fresh tumour tissue specimen was immediately embedded in optimum cutting temperature compound (Miles, Kankakee, IL, USA), and frozen in liquid nitrogen immediately after surgical resection and maintained at $-80^{\circ} \mathrm{C}$ until use. Frozen sections were cut on a cryostat to a thickness of $6 \mu \mathrm{m}$ and were stained with haematoxylin and eosin and used for immunohistochemical staining. After the connective tissues were trimmed off, the other-half of the tumour specimen that was then made up of more than $80 \%$ cancer cells was used for the reverse transcriptasepolymerase chain reaction (RT-PCR) analysis.

\section{Immunohistochemical assays}

The assays were carried out as described previously (Hashida et al, 2002a). Endogenous peroxidases were blocked by incubating with $0.3 \% \mathrm{H}_{2} \mathrm{O}_{2}$ in absolute methanol for $30 \mathrm{~min}$. The sections were then incubated with $5 \%$ bovine serum albumin for $2 \mathrm{~h}$ at room temperature. Subsequently, replicate sections were incubated for $2 \mathrm{~h}$ with the anti-MRP-1/CD9 MAb M31-15, the anti-KAI1/CD82 MAb C33 and the anti-CD151 MAb SFA1.2B4, respectively. After washing three times in phosphate-buffered saline (PBS), they were then incubated for $1 \mathrm{~h}$ with biotinylated horse anti-mouse IgG

Table I Relation of MRP-I/CD9, KAII/CD82 and CDI5I expression and various prognostic factors in I46 patients with colon cancer

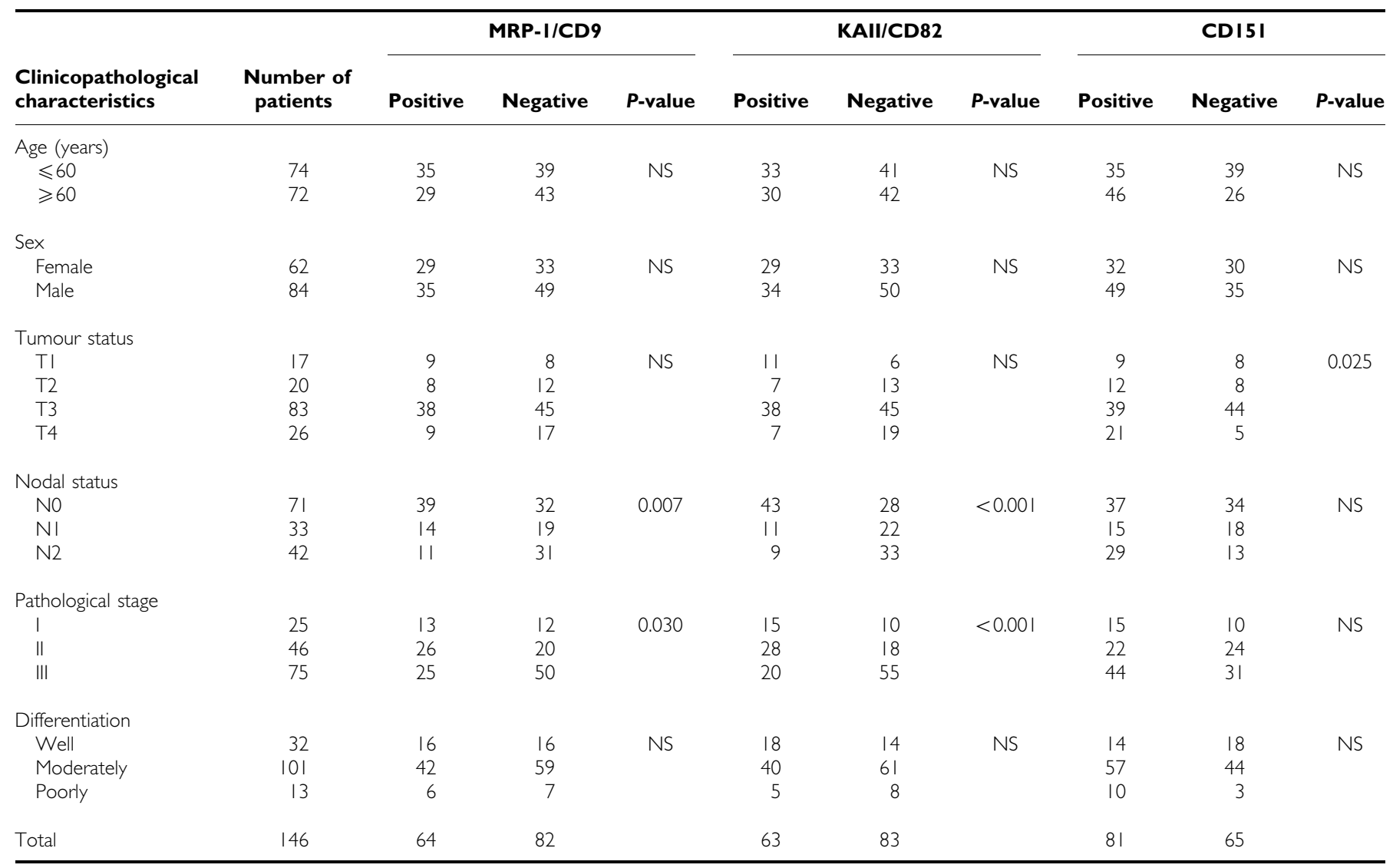

NS = not significant. 
(Vector Laboratories Inc., Burlingame, CA, USA). Visualisation of the antibody binding was completed using 3,3'-diaminobenzidine tetrahydrochloride, and the sections were lightly counterstained with Mayer's haematoxylin. Sections incubated with mouse myeloma SP2 supernatant and mouse IgG were used as negative reaction control. Specimens of fibroadenoma of the breast were used as a positive control.

The samples were classified by two pathologists who had no knowledge of patients' clinical status. All sections were scored in semiquantitative fashion according to the method described previously (Huang et al, 1998). Briefly, we determined the score by estimating the percentage of cells that stained for MRP-1/CD9, KAI1/CD82 and CD151, and multiplying by the assessment of the intensity of the stain on a $0,1+, 2+$ or $3+$ scale $(0$, no staining; $1+$, weak staining; $2+$, distinct staining; $3+$, very strong staining). The theoretical limits of the scores ranged from $0(0 \%$ of cells staining) to $300(100 \%$ of the cells staining at $3+$ intensity). Significant differences were found with respect to the survival rate when a score of 120 was used as a cut off value. Specimens with a score of $\geqslant 120$ were classified as positive, and when score was $<120$, specimens were classified as negative.

\section{Semiquantitative RT - PCR analysis}

Reverse transcriptase-polymerase chain reaction was performed as described previously in order to confirm the results of MRP-1/ CD9, KAI1/CD82 and CD151 expression in immunohistochemical studies (Adachi et al, 1996). Total cellular RNA was extracted from the frozen tumour tissues by the acid guanidium thiocyanate procedure (Chomczynski and Sacchi, 1987). First-strand complementary DNA (cDNA) synthesis was performed with $5 \mu \mathrm{g}$ of total RNA using a cDNA synthesis kit (Pharmacia, Piscataway, NJ, USA) following the manufacturer's protocol. We used $1 \mu \mathrm{l}$ aliquot of the reaction mixture for PCR amplification. We titrated the amount of starting cDNA and determined the number of amplification cycles to obtain reproducible quantitative performance of the RT-PCR assay for $M R P-1 / C D 9, K A I 1 / C D 82$ and $C D 151$. The generated cDNA was amplified using primers for MRP-1/CD9 (5'-TGCATCTGTATCCAGCGCCA $-3^{\prime}$ and $5^{\prime}$-CTCAGGGATGTAAGCTGACT- $3^{\prime}$ ), KAI1/CD82 (5'-AGTCCTCCCTGCTGCTGTGTG- $3^{\prime}$ and $5^{\prime}$-TCAGTCAGGGTGGGCAAGAGG- $\left.{ }^{\prime}\right)$ and CD151 (5'-ATGGGTGAGTTCAACGAGAAG- $3^{\prime}$ and $5^{\prime}$-TCAGTAGTGCTCCAGCTTC-AG-3'). The internal control was $\beta$-actin (5'-GATATCGCCGCGCTCGTCGTCGAC- $3^{\prime}$ and $5^{\prime}$-CAGGAAGGAAGGCTGGAAGAGTGC- $\left.3^{\prime}\right)$. All of the subsequent assays were then performed under conditions that produced amplifications of MRP-1/CD9, KAI1/ $C D 82, C D 151$ and $\beta$-actin within a linear range. A total of 24 cycles of PCR amplification was performed for MRP-1/CD9, KAI1/CD82 and $\beta$-actin, and 20 cycles for $C D 151$ as follows: denaturation at $94^{\circ} \mathrm{C}$ for $40 \mathrm{~s}$, annealing at $60^{\circ} \mathrm{C}$ for $40 \mathrm{~s}$ and extension at $72^{\circ} \mathrm{C}$ for $90 \mathrm{~s}$. The same PCR conditions were used to amplify the $\beta$-actin DNA. Tubes containing all of the ingredients except templates were included in all runs and served as negative controls. Preparations of the human endothelial cell line ECV304, which is positive for $M R P-1 / C D 9, K A I 1 / C D 82$ and $C D 151$, were used as a positive control. The amplified PCR products were electrophoresed on a $1 \%$ agarose gel containing ethidium bromide, and the bands were visualised under ultraviolet light followed by densitometric analysis. In addition, the resulting PCR products were analysed by sequencing to confirm their identity as described previously (Onuma et al, 1999; Rae et al, 2000). PCR products were successfully sequenced. Sequence comparisons coincided with the known MRP-1/CD9, KAI1/CD82 and CD151 genes.

The densitometric values obtained for MRP-1/CD9, KAI1/CD82 and $C D 151$ bands in a given tumour tissue sample were divided by the corresponding value of $\beta$-actin for normalisation, and the ratio was referred to as the gene expression ratio for each gene. The

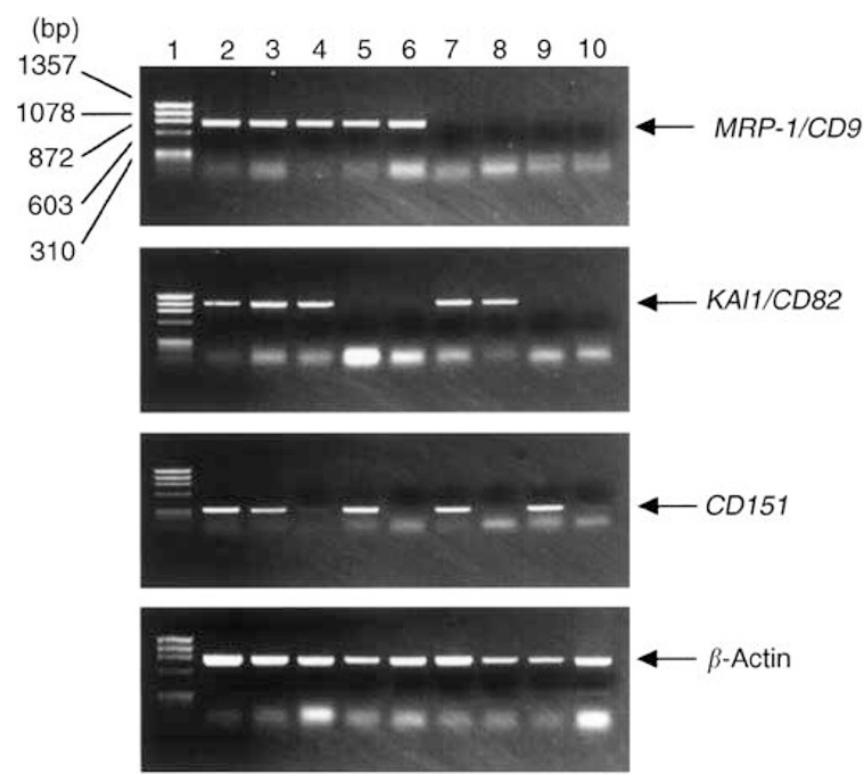

Figure I Agarose gel electrophoresis of RT-PCR-amplified MRP-I/CD9, KAll/CD82, CD/5/ and $\beta$-actin. Lane I, size marker; lane 2, human endothelial cell line ECV304(positive control); lane 3, colon cancer with MRP-I/CD9-, KAll/CD82- and CD/5I-positive expression; lane 4, colon cancer with MPR-I/CD9- and KAll/CD82-positive but CD/5/-negative expression; lane 5, colon cancer with MRP- //CD9- and CD / $/$ - -positive but KAll/CD82-negative expression; lane 6, colon cancer with MRP-I/CD9positive but KAII/CD82- and CDI5I-negative expression; lane 7, colon cancer with KAII/CD82- and CD / $/$-positive but MRP- //CD9-negative expression; lane 8, colon cancer with KAl//CD82-positive but MRP-I/CD9- and CD/5/negative expression; lane 9, colon cancer with $C D / 5$ I-positive but MRP- I/ CD9- and KAll/CD82-negative expression; lane 10, colon cancer with MRPI/CD9-, KAll/CD82- and CD/51-negative expression.

expression ratio of the tumour was then divided by that of the human endothelial cell line ECV304 to obtain the gene conservation rate for $M R P-1 / C D 9, K A I 1 / C D 82$ and $C D 151$. We arbitrarily set several cutoff values to select the best value. When 0.8 was used as a cutoff value, significant differences were found in survival. We therefore selected 0.8 as the most appropriate cutoff value. When the conservation rate value of a given specimen was $\geq 0.8$, it was considered to indicate positive gene expression. If the value was $<0.8$, it was considered to indicate negative gene expression (Figure 1).

\section{Statistical analysis}

The statistical significance of the difference between the incidence of $M R P-1 / C D 9, K A I 1 / C D 82$ and $C D 151$ expression and clinical and pathologic parameters was assessed by the $\chi^{2}$ test or Mann-Whitney U-test. Overall cancer-specific survival was defined as from the date of surgery to the date of death due to cancer. The Kaplan-Meier method was used to estimate the probability of overall survival as a function of time (Kaplan and Meier, 1958) and was compared using the log-rank test (Mantel, 1966). Multivariate analysis was performed using the Cox regression model (Cox, 1972) to study the effects of different variables on survival, and eight factors (MRP-1/CD9 status, KAI1/CD82 status, CD151 status, sex, age, tumour status, nodal status and histological differentiation) were studied. Scores were assigned to each variable for regression analysis. All $P$-values were based on two-tailed statistical analysis, and a $P$-value of $<0.05$ was considered to indicate statistical significance. 


\section{RESULTS}

MRP-1/CD9, KAI1/CD82 and CD151 gene expression in colon cancer tissues analysed by RT-PCR

Of the 146 colon cancers studied, 82 carcinomas (43.8\%) were evaluated as $M R P-1 / C D 9$-positive and 64 carcinomas $(56.2 \%)$ as $M R P-1 / C D 9-n e g a t i v e$ expression. In all, 63 carcinomas (43.2\%) were evaluated as KAI1/CD82-positive and 83 carcinomas $(56.8 \%)$ as KAI1/CD82-negative expression. A total of 81 carcinomas $(55.5 \%)$ were evaluated as CD151-positive and 65 carcinomas (44.5\%) as CD151-negative expression (Table 1 and Figure 1).

\section{Immunohistochemical study of MRP-1/CD9, KAI1/CD82 and CD151 in colon cancer tissues}

Of the 146 colon cancers studied using the immunohistochemical method, $69(49.1 \%)$ were classified as MRP-1/CD9 positive (Figure 2A), and the immunostaining was intense and uniform on the cell surface membrane in these specimens. There were 77 specimens (50.9\%) with negative MRP-1/CD9 expression (Figure 2B). The immunohistochemical results agreed well with those from the RT-PCR assays, and $92.5 \%$ of the specimens coincided exactly.
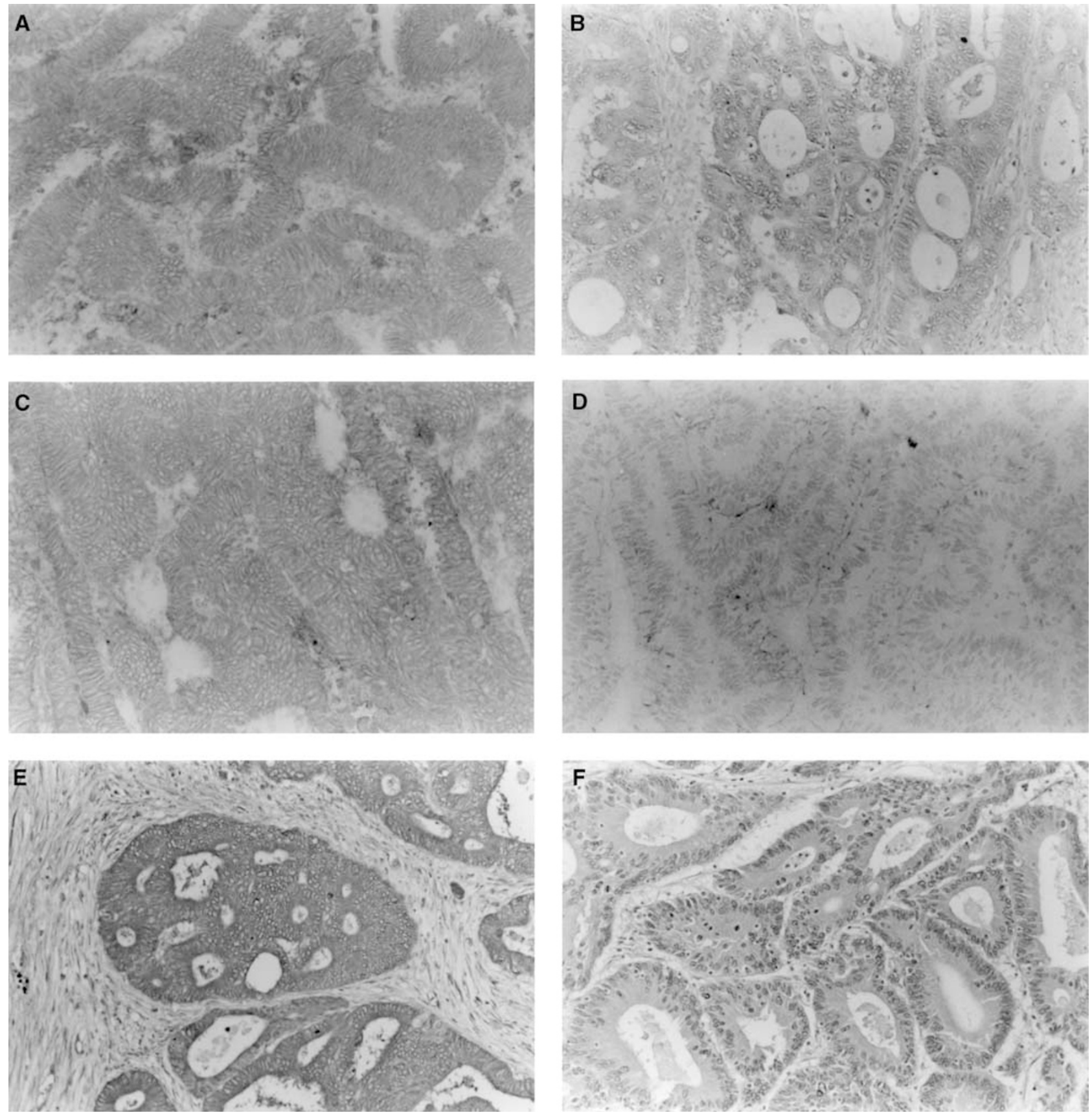

Figure 2 Immunohistochemical staining of human colon cancer tissues using the avidin-biotin-peroxidase complex procedure (original magnification, $\times$ 150). (A) MRP- //CD9-positive staining of colon cancer; (B) MRP-//CD9 negative staining of colon cancer; (C) KAll/CD82-positive staining of colon cancer; (D) KAl //CD82-negative staining of colon cancer; (E) CD I 5 / -positive staining of colon cancer; (F) CD / 5 I-negative staining of colon cancer. 
Turning to the KAI1/CD82, there were 67 specimens (45.9\%) with positive KAI1/CD82 expression and 79 specimens $(54.1 \%)$ with negative KAI1/CD82 expression (Figure 2C, D). These results agreed well with those from the RT-PCR assays, and $93.4 \%$ of the specimens coincided exactly.

Furthermore, there were 78 specimens (53.4\%) with positive CD151 expression and 68 specimens $(46.6 \%)$ with negative CD151 expression (Figure 2E, F). These results agreed with those from the RT-PCR assays, and $88.9 \%$ of the specimens coincided exactly.

\section{Relation between MRP-1/CD9, KAI1/CD82 and CD151 expression and various prognostic factors}

The relation between $M R P-1 / C D 9$ gene expression and various prognostic factors is shown in Table 1 . The relation was found between $M R P-1 / C D 9$ gene expression and nodal status $(P=0.007)$ and pathological stage $(P=0.030)$. In all, $32(45.1 \%)$ patients with N0 stage had negative gene expression compared with $57.6 \%$ of N1 stage patients and $75.6 \%$ of $\mathrm{N} 2$ stage patients. In addition, the percentage of patients whose tumours had $M R P-1 / C D 9$-negative gene expression increased from $48.0 \%$ of those with stage I to $66.7 \%$ of those with stage III.

In contrast, KAI1/CD82 gene expression was associated with lymph node status $(P<0.001)$ as well as pathological stage $(P<0.001)$. A total of $28(39.4 \%)$ patients with N0 stage had negative gene expression compared with $66.7 \%$ of $\mathrm{N} 1$ stage patients and $78.6 \%$ of $\mathrm{N} 2$ stage patients. With respect to pathological stage, the percentage of patients whose tumours had KAI1/CD82-negative gene expression increased from $40.0 \%$ of those with stage I to $73.3 \%$ of those with stage III.

The relation between CD151 gene expression and various prognostic factors is shown in Table 1 . There was a statistically significant relation between gene expression and tumour status $(P=0.025)$. Eight patients $(47.1 \%)$ with $\mathrm{T} 1$ stage had negative gene expression compared with $19.2 \%$ of $\mathrm{T} 4$ stage patients.

\section{Relation between MRP-1/CD9 expression and 3-year,} disease-free and overall survival of colon cancer patients

Among all 146 patients, the 3-year survival rate of patients with $M R P-1 / C D 9$-positive tumours was significantly higher than that of patients with $M R P-1 / C D 9$-negative tumours $(98.1$ vs $76.0 \%$, $P<0.001$; Table 2). In addition, the disease-free survival rate of patients with $M R P-1 / C D 9$-positive tumours was significantly higher than that of patients with $M R P-1 / C D 9$-negative tumours (74.8 vs $43.5 \%, P=0.004$; Table 2 ). Similarly, the overall survival rate for patients with positive tumours was significantly better than that of individuals whose tumours had negative $M R P-1 / C D 9$ expression (89.8 vs 50.8\%, $P<0.001$; Table 2 and Figure 3 ). In particular, $M R P-1 / C D 9$ was an effective indicator for patients with advanced disease (N2 status and stage III).

\section{Relation between KAI1/CD82 expression and 3-year, disease-free and overall survival of colon cancer patients}

Among the 146 patients, the 3-year survival rate of patients with KAI1/CD82-positive tumours was significantly higher than that of patients with KAI1/CD82-negative tumours (98.2 vs $75.7 \%$, $P<0.001$; Table 3 ). In addition, the disease-free survival rate of patients with $K A I 1 / C D 82$-positive tumours was significantly higher than that of patients with KAI1/CD82-negative tumours (77.1 vs $42.3 \%, P=0.004$; Table 3 ). Moreover, the overall survival rate for patients with positive tumours was significantly better than that of

Table 2 Survival rate of 146 patients with colon cancer according to clinicopathological characteristics and MRP-I/CD9

\begin{tabular}{|c|c|c|c|c|c|c|c|c|c|}
\hline Clinicopathological characteristics & \multicolumn{3}{|c|}{ 3-year survival rate $(\%)$} & \multicolumn{3}{|c|}{ Disease-free survival rate (\%) } & \multicolumn{3}{|c|}{ Overall survival rate (\%) } \\
\hline Age (years) & & & & & & & & & \\
\hline$\geqslant 60$ & 100.0 & 65.8 & 0.004 & 67.5 & 25.3 & 0.051 & 92.3 & 47.5 & 0.002 \\
\hline \multicolumn{10}{|l|}{ Sex } \\
\hline \multicolumn{10}{|l|}{ Tumour status } \\
\hline $\mathrm{TI}$ & 100.0 & 100.0 & $>0.999$ & 100.0 & 50.0 & 0.400 & 100.0 & 50.0 & 0.400 \\
\hline T2 & 100.0 & 66.7 & 0.192 & 77.2 & 33.3 & 0.118 & 80.0 & 33.3 & 0.260 \\
\hline T3 & 100.0 & 94.4 & 0.499 & 75.0 & 23.3 & 0.174 & 95.2 & 72.4 & 0.042 \\
\hline T4 & 83.3 & 29.4 & 0.041 & 50.1 & 12.3 & 0.170 & 55.6 & 15.7 & 0.047 \\
\hline \multicolumn{10}{|l|}{ Pathological stage } \\
\hline 1 & 100.0 & 100.0 & $>0.999$ & 72.2 & 23.7 & 0.789 & 100.0 & 75.0 & 0.400 \\
\hline$\|$ & 100.0 & 100.0 & $>0.999$ & 85.2 & 54.4 & 0.236 & 91.7 & 75.0 & 0.690 \\
\hline III & 95.2 & 60.7 & 0.006 & 79.0 & 34.7 & 0.013 & 82.9 & 37.2 & 0.002 \\
\hline \multicolumn{10}{|l|}{ Differentiation } \\
\hline Well & 100.0 & 86.7 & $>0.999$ & 83.3 & 28.4 & 0.469 & 100.0 & 34.2 & $>0.999$ \\
\hline Moderately & 97.1 & 78.7 & 0.019 & 80.1 & 27.8 & 0.074 & 85.0 & 64.5 & 0.049 \\
\hline Poorly & 100.0 & 20.0 & 0.015 & 100.0 & 0.0 & 0.008 & 100.0 & 0.0 & 0.008 \\
\hline Total & 98.1 & 76.0 & $<0.001$ & 74.8 & 43.5 & 0.004 & 89.8 & 50.8 & $<0.001$ \\
\hline
\end{tabular}


individuals whose tumours had negative KAI1/CD82 expression (84.8 vs $54.9 \%, P=0.002$; Table 3 and Figure 4 ).

\section{Relation between CD151 expression and 3-year, disease-} free and overall survival of colon cancer patients

Among all 146 patients, the 3-year survival rate of patients with CD151-positive tumours was significantly lower than that of patients with $C D 151$-negative tumours (78.5 vs $94.3 \%, P=0.012$; Table 4). In addition, the disease-free survival rate of patients with

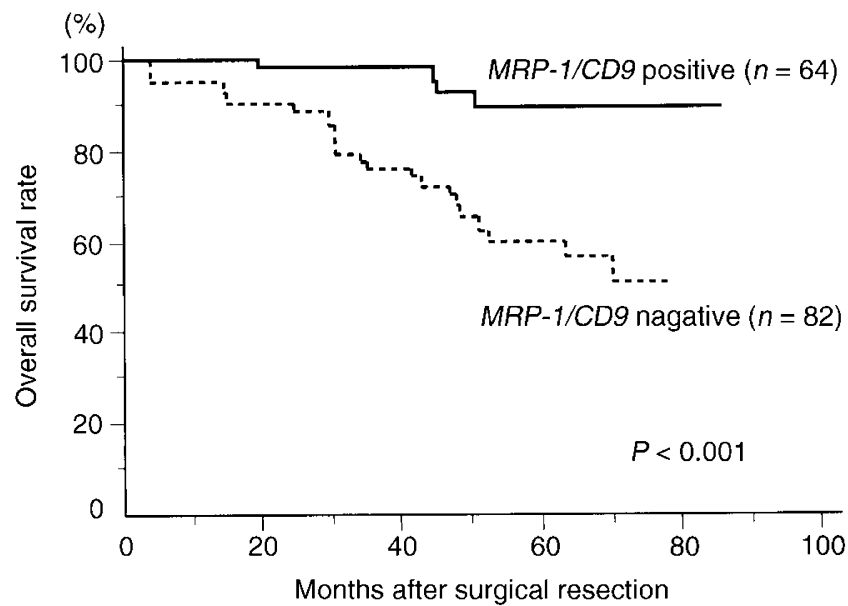

Figure 3 Overall survival of 146 colon cancer patients according to their tumour MRP- //CD9 gene status.
CD151-positive tumours was significantly lower than that of patients with $C D 151$-negative tumours (53.6 vs $61.2 \%, P=0.048$; Table 4). Moreover, the overall survival rate for patients with negative tumours was significantly better than that of individuals whose tumours had positive CD151 expression (61.2 vs 74.9\%, $P=0.022$; Table 4 and Figure 5).

\section{Prognostic value of MRP-1/CD9, KAI1/CD82 and CD151 expression}

The Cox regression model was used to evaluate disease-free and overall survival as shown in Table 5. Two variables, nodal status $(P<0.001)$ and $M R P-1 / C D 9$ status $(P=0.015)$, were significant factors in predicting the disease-free survival of colon cancer patients. Moreover, three variables, nodal status $(P<0.001)$, tumour status $(P=0.029)$ and $M R P-1 / C D 9$ status $(P=0.015)$, were significant factors in predicting the overall survival of colon cancer patients.

\section{DISCUSSION}

Colon cancer has become one of the most common causes of cancer death in Japan (Health and Welfare Statistics Association, 1998). Endoscopic treatments for early stage of colon cancer have been improved, but no established treatment is available for patients in the advanced stage. Up until now, the prognosis of patients with colon cancer has depended on the clinicopathological staging. However, recently, molecular assessment has been incorporated into treatment of patients with colon cancer (Boland et al, 2000). It is well known that the accumulation of genetic alterations facilitates the progression of tumours. The famous model of colorectal tumorigenesis shows that three tumour

Table 3 Survival rate of I 46 patients with colon cancer according to clinicopathological characteristics and KAII/CD82

\begin{tabular}{|c|c|c|c|c|c|c|c|c|c|}
\hline \multirow[b]{2}{*}{ Clinicopathological characteristics } & \multicolumn{3}{|c|}{ 3-year survival rate $(\%)$} & \multicolumn{3}{|c|}{ Disease-free survival rate (\%) } & \multicolumn{3}{|c|}{ Overall survival rate (\%) } \\
\hline & Positive & Negative & $P$-value & Positive & Negative & $P$-value & Positive & Negative & $P$-value \\
\hline \multicolumn{10}{|l|}{ Age (years) } \\
\hline$\geqslant 60$ & 100.0 & 63.7 & 0.001 & 50.8 & 36.7 & 0.020 & 78.7 & 51.5 & 0.006 \\
\hline \multicolumn{10}{|l|}{ Sex } \\
\hline Female & 100.0 & 84.8 & 0.112 & 100.0 & 33.3 & 0.021 & 100.0 & 60.6 & 0.013 \\
\hline \multicolumn{10}{|l|}{ Tumour status } \\
\hline $\mathrm{TI}$ & 100.0 & 100.0 & $>0.999$ & 100.0 & 0.0 & 0.250 & 100.0 & 0.0 & 0.200 \\
\hline $\mathrm{T} 2$ & 100.0 & 70.5 & 0.209 & 100.0 & 0.0 & 0.036 & 100.0 & 0.0 & 0.048 \\
\hline $\mathrm{T} 3$ & 100.0 & 94.2 & 0.495 & 75.0 & 66.3 & 0.413 & 81.2 & 83.7 & 0.863 \\
\hline T4 & 80.0 & 33.8 & 0.115 & 35.6 & 20.3 & 0.480 & 40.0 & 22.1 & 0.190 \\
\hline \multicolumn{10}{|l|}{ Nodal status } \\
\hline \multicolumn{10}{|l|}{ Pathological stage } \\
\hline I & 100.0 & 100.0 & $>0.999$ & 66.7 & 0.0 & $<0.001$ & 100.0 & 66.7 & 0.300 \\
\hline$\|$ & 100.0 & 100.0 & $>0.999$ & 100.0 & 40.9 & 0.236 & 100.0 & 45.8 & 0.400 \\
\hline III & 94.1 & 64.2 & 0.025 & 53.1 & 45.6 & 0.556 & 61.0 & 49.1 & 0.173 \\
\hline \multicolumn{10}{|l|}{ Differentiation } \\
\hline Well & 100.0 & 84.6 & 0.192 & 75.0 & 18.8 & 0.035 & 83.3 & 30.8 & 0.138 \\
\hline Moderately & 97.1 & 78.7 & 0.020 & 55.5 & 46.5 & 0.126 & 87.4 & 62.4 & 0.021 \\
\hline Poorly & 100.0 & 33.3 & 0.061 & 75.0 & 25.6 & 0.090 & 75.0 & 33.3 & 0.103 \\
\hline Total & 98.2 & 75.7 & $<0.001$ & 77.1 & 42.3 & $<0.001$ & 84.8 & 54.9 & 0.002 \\
\hline
\end{tabular}


suppressor genes, $p 53, A P C$ and $D C C$, and the dominant oncogene $\mathrm{K}$-ras play key roles in the progression of colon cancer (Feason and Vogelstein, 1990). In addition, many other prognostic factors have been examined for colon cancer. However, little is understood about the genetic alternations and cellular mechanisms that are responsible for the final steps in tumour metastasis (Haier et al, 2000). An enhanced understanding of the molecular genetic events that occur during progression in colon cancer could lead to new therapeutic modalities and improvement in survival rates.

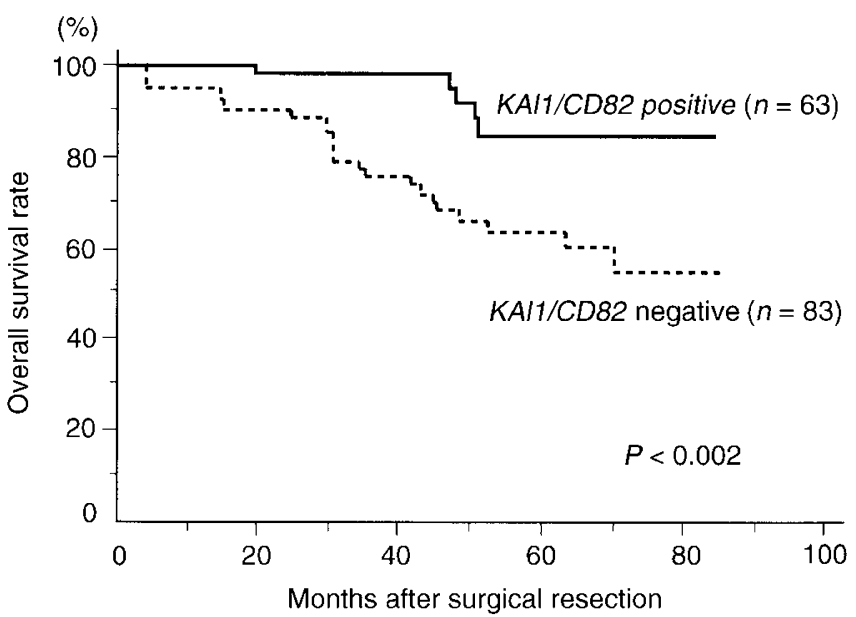

Figure 4 Overall survival of I 46 colon cancer patients according to their tumour KAll/CD82 gene status.
In the present study, we investigated the gene expressions of the three TM4SF members, MRP-1/CD9, KAI1/CD82 and CD151. This TM4SF is made up of approximately 23 members. These proteins are variously expressed in leucocytes and a variety of nonhaematopoietic tissues. MRP-1/CD9 is a glycoprotein widely expressed not only in haematopoietic tissues, platelets, early $B$ cells, activated $\mathrm{T}$ cells and granulocytes, but also in nonhaematopoietic tissues (Wright and Tomlinson, 1994). CD9 null female displays a severe reduction in fertility and CD9 appears to be essential for sperm-egg fusion, a process involving the CD9-associated integrin $\alpha 6 \beta 1$ (Le Naour et al, 2000). TM4SF proteins act as links between extracellular integrins and intracellular signalling molecules, such as phosphatidylinositol 4-kinase (Yauch et al, 1998) and TM4SF proteins appear to regulate cell motility through this link (Hemler, 1996; Berditchevski and Odintsova, 1999). Several studies suggest that TM4SF plays an important role in the regulation of cell development, activation, proliferation and adhesion (Wright and Tomlinson, 1994; Hemler et al, 1996; Hashida et al, 2002b). Interestingly, several TM4SF member proteins have been associated with the metastatic phenotype, but these associations have been, for the most part, negative. Previously, we showed that reductions of $M R P-1 / C D 9$ and KAI1/CD82 were predictive factors for a poor prognosis in patients with various kinds of cancers. As part of our evaluation of members of TM4SF as possible prognostic predictors, we further extended our study to the expression of $C D 151$ and performed a retrospective study on the expression of $C D 151, M R P-1 / C D 9$ and KAI1/CD82 in colon cancer. CD151 was reported to be a metastasis-associated antigen that appeared to contribute positively to the metastatic phenotype in contrast to the MRP-1/CD9, KAI1/CD82 and ME491/CD63 (Testa et al, 1999). In addition, it was reported that CD151 may not affect tumour cell proliferation

Table 4 Survival rate of I 46 patients with colon cancer according to clinicopathological characteristics and CD I5 I

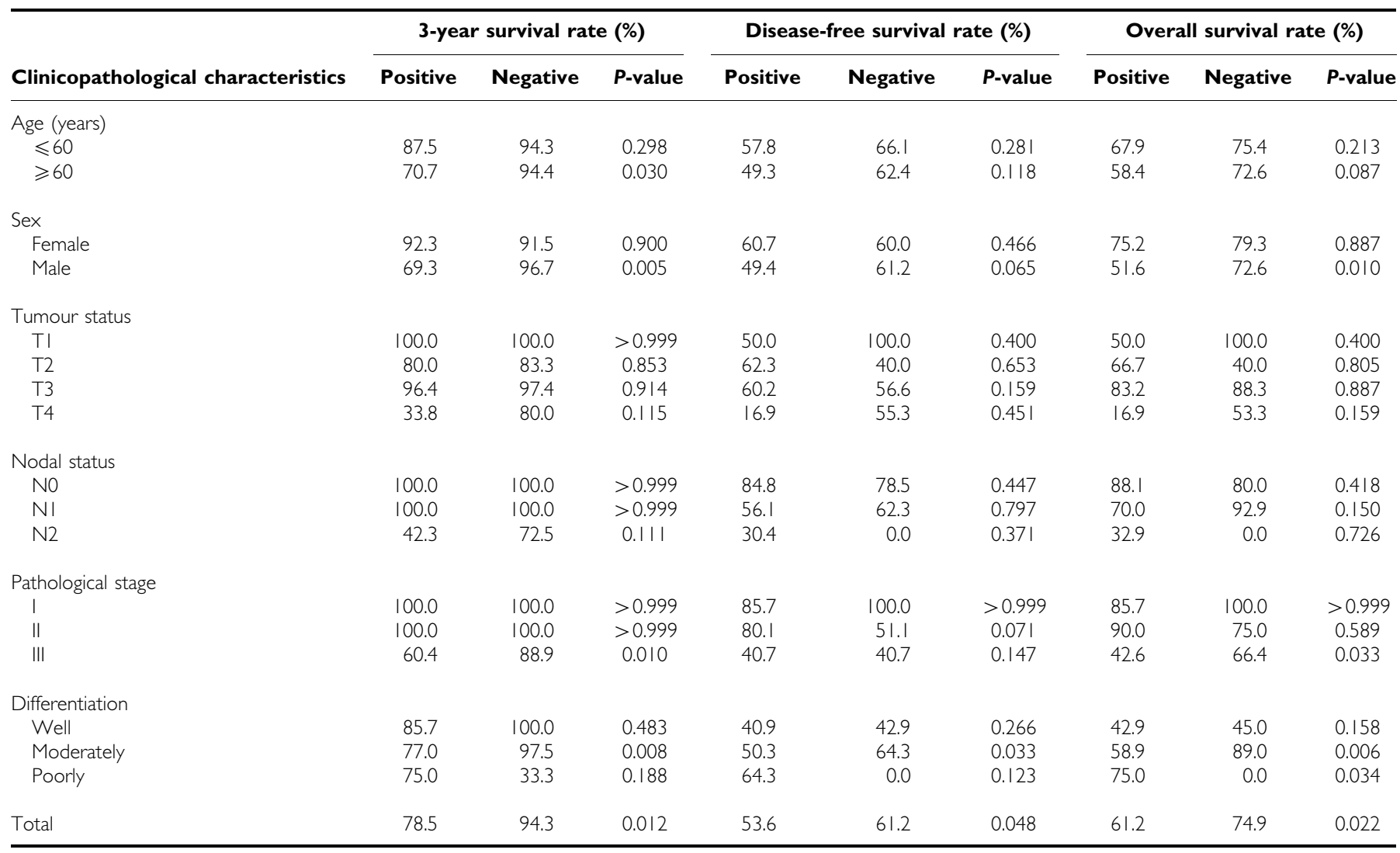


but could be involved in an early step in the formation of secondary metastatic lesions. The ability of CD151 to mediate tumour cell migration may provide a possible mechanism for the role of this protein in effecting metastatic dissemination. More-

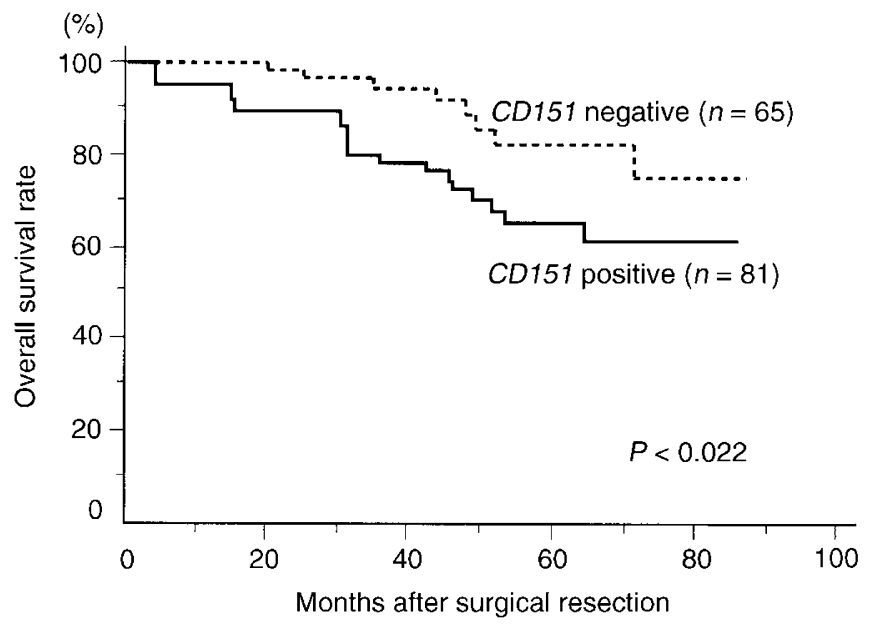

Figure 5 Overall survival of I 46 colon cancer patients according to their tumour CDI 5 / gene status. over, it was reported that the CD151 molecule enhances cell motility, invasion and metastasis of cancer cells and that focal adhesion kinase is needed for these events through CD151 (Kohno et al, 2002). We have hypothesised that those patients with a CD151-positive tumour are in a more advanced stage of the disease and have a much poorer prognosis. In this study, the CD151 mRNA levels and protein expression were associated with tumour status. Moreover, our present study showed that there was a significant difference between the overall survival rate for colon cancer patients with low CD151 expression and that of patients with CD151-positive tumours. These findings suggest that CD151 may play an important role in the progression in colon cancer cells, and that its expression may have an effect on the characteristics of colon cancers. Further basic studies using an experimental metastasis model will be necessary.

On the other hand, KAI1/CD82 expression was demonstrated to be consistently downregulated during the progression of human colon cancer, as well as breast cancer (Huang et al, 1998), pancreatic cancer (Sho et al, 1998) and nonsmall cell lung cancer (Adachi et al, 1996). Furthermore, we have shown that the survival rate for colon cancer patients with negative KAI1/CD82 expression was strikingly lower than that of patients with KAI1/CD82-positive tumours. Similarly, the survival rate of patients with MRP-1/CD9negative tumours was significantly lower than that of patients with MRP-1/CD9-positive tumours. The malignancy-suppressing effect of CD82 or CD9 may be based partially on cell motility inhibition

Table 5 Multivariate regression analysis in predicting the disease-free and overall survival of I 46 patients with colon cancer

\begin{tabular}{|c|c|c|c|c|c|}
\hline \multirow[b]{2}{*}{ Variables } & \multirow[b]{2}{*}{$\begin{array}{l}\text { Assigned } \\
\text { score }\end{array}$} & \multicolumn{2}{|c|}{ Disease-free survival } & \multicolumn{2}{|c|}{ Overall survival } \\
\hline & & $\begin{array}{l}\text { Hazard ratio } \\
(95 \% \mathrm{Cl})\end{array}$ & $P$-value & $\begin{array}{c}\text { Hazard } \\
\text { ratio }(95 \% \mathrm{Cl})\end{array}$ & $P$-value \\
\hline \multicolumn{6}{|l|}{ MRP-I/CD9 } \\
\hline Positive & 0 & $3.147(1.240-7.940)$ & 0.015 & $5.511(1.584-19.158)$ & 0.007 \\
\hline Negative & I & & & & \\
\hline \multicolumn{6}{|l|}{ KAll/CD82 } \\
\hline Positive & 0 & $0.949(0.388-2.321)$ & 0.909 & I. $107(0.364-3.369)$ & 0.858 \\
\hline Negative & I & & & & \\
\hline \multicolumn{6}{|l|}{$C D \mid 51$} \\
\hline Negative & 0 & $0.529(0.247-1.123)$ & 0.097 & $0.603(0.028-1.597)$ & 0.309 \\
\hline Positive & I & & & & \\
\hline \multicolumn{6}{|l|}{ Age (years) } \\
\hline$\leqslant 60$ & 0 & I.49| (0.748-2.974) & 0.257 & $1.258(0.569-2.782)$ & $0.57 \mid$ \\
\hline$\geqslant 60$ & I & & & & \\
\hline \multicolumn{6}{|l|}{ Sex } \\
\hline Female & 0 & $1.374(0.699-2.702)$ & 0.357 & $1.838(0.786-4.300)$ & 0.160 \\
\hline Male & I & & & & \\
\hline \multicolumn{6}{|l|}{ Tumour status } \\
\hline TI & I & $1.56 \mid(0.942-2.585)$ & 0.084 & $2.066(1.101-3.874)$ & 0.024 \\
\hline T2 & 2 & & & & \\
\hline T3 & 3 & & & & \\
\hline T4 & 4 & & & & \\
\hline \multicolumn{6}{|l|}{ Nodal status } \\
\hline No & 0 & $2.812(1.736-4.556)$ & $<0.001$ & $3.797(1.981-7.277)$ & $<0.001$ \\
\hline $\mathrm{NI}$ & I & & & & \\
\hline N2 & 2 & & & & \\
\hline \multicolumn{6}{|l|}{ Differentiation } \\
\hline Well & 0 & 0.811 (0.422-1.559) & 0.530 & $0.815(0.384-1.728)$ & 0.593 \\
\hline Moderately & I & & & & \\
\hline Poorly & 2 & & & & \\
\hline
\end{tabular}

Abbreviation: $\mathrm{Cl}=$ confidence interval. 
and apoptosis induction promoted by concurrent GM3 synthesis and $N$-glycosylation (Ono et al, 1999). Although the precise mechanism remains unknown, the levels of the $M R P-1 / C D 9$ or $K A I 1 / C D 82$ gene may be diminishing due to promoter abnormality or aberrant glycosylation may have occurred in the first hydrophilic region and normal MRP-1/CD9 or KAI1/CD82 function could be lost. Hence, GM3 and other lipids may contribute to the formation of tetraspanin/tetraspanin complexes. Our present study suggests that cancer progression may lead to collapse of tetraspanin/tetraspanin complexes as well as the collapse of tetraspanin/ integrin complexes. In addition, a link between a tetraspanin and Rho GTPase cascade may explain why members of TM4SF are involved in cell activation, adhesion, growth and metastasis (Delaguillaumie et al, 2002). Although the precise biological functions of these proteins remain unknown, the downregulation of KAI1/CD82 and MRP-1/CD9 genes during the progression of human cancer is highly associated with a poor prognosis.

The classification of colon cancers according to MRP-1/CD9, KAI1/CD82 and CD151 expression might be useful in identifying patients for whom intensive adjuvant therapy is warranted. It is conceivable that testing tumours for TM4SF expression, in combination with other molecular and biochemical assays, may improve the prognostic evaluation of colon cancer patients, and enhance the clinician's ability to prospectively identify patients who will have early disease recurrence and who require adjuvant chemotherapy.

\section{ACKNOWLEDGEMENTS}

We thank Drs Tadashi Ohbayashi and Tomoko Okuno for the histological examination of the tumour samples, and Mitsuko Shirata for her assistance in preparation of the manuscript. This work was supported in part by Grants-in-Aid 14370421 from the Ministry of Education, Science, Sports and Culture of Japan (to $\mathrm{MM}$ ) and the Vehicle Racing Commemorative Foundation (to MM).

\section{REFERENCES}

Adachi M, Taki T, Ieki Y, Huang C, Higashiyama M, Miyake M (1996) Correlation of KAI1/CD82 gene expression with good prognosis in patients with non-small cell lung cancer. Cancer Res 56: $1751-1755$

Berditchevski F, Odintsova E (1999) Characterization of integrintetraspanin adhesion complexes: role of tetraspanins in integrin signaling. J Cell Biol 146: 477-492

Boland CR, Sinicrope FA, Brenner DE, Carethers JM (2000) Colorectal cancer prevention and treatment. Gastroenterology 118: S115-S128

Chomczynski P, Sacchi N (1987) Single-step method of RNA isolation by acid guanidium thiocyanate-phenol-chloroform extraction. Anal Biochem 162: $156-159$

Cox DR (1972) Regression models and life-tables. J R Stat Soc B 34: 187 220

Delaguillaumie A, Lagaudriere-Gesbert C, Popoff MR, Conjeaud H (2002) Rho GTPases link cytoskeletal rearrangements and activation processes induced via the tetraspanin CD82 in T lymphocytes. J Cell Sci 115: $433-$ 443

Dong J-T, Lamb PW, Rinker-Schaeffer CW, Vukanovic J, Ichikawa T, Isaacs JT, Barrett JC (1995) KAI-1, a metastasis suppressor gene for prostate cancer on human chromosome 11p11.2. Science (Washington DC) 268: $884-886$

Dong J-T, Suzuki H, Pin SS, Bova GS, Schalken JA, Isaacs WB, Barrett JC, Isaacs JT (1996) Down-regulation of the KAI1 metastasis suppressor gene during the progression of human prostatic cancer infrequently involves gene mutation or allelic loss. Cancer Res 56: 4387-4390

Feason ER, Vogelstein BA (1990) A genetic model of colorectal tumorigenesis. Cell 61: 759-761

Fitter S, Tetaz TJ, Berndt MC, Ashman LK (1995) Molecular cloning of cDNA encoding a novel platelet-endothelial cell tetra-span antigen, PETA-3. Blood 86: $1348-1355$

Haier J, Nasralla M, Nicolson GL (2000) Cell surface molecules and their prognostic values in assessing colorectal carcinomas. Ann Surg 231: 11 24

Hasegawa H, Utsunomiya Y, Kishimoto K, Yanagisawa K, Fujita S (1996) $S F A-1$, a novel cellular gene induced by human T-cell leukemia virus type 1 , is a member of the transmembrane 4 superfamily. J Virol 70: 3258 3263

Hashida H, Takabayashi A, Adachi M, Imai T, Kondo K, Kohno N, Yamaoka Y, Miyake M (2001) The novel monoclonal antibody MH8-4 inhibiting cell motility recognizes integrin $\alpha 3$ : inverse of its expression with metastases in colon cancer. Int J Oncol 18: 89-95

Hashida H, Takabayashi A, Kanai M, Adachi M, Kondo K, Kohno N, Yamaoka Y, Miyake M (2002a) Aminopeptidase $\mathrm{N}$ is involved in cell motility and angiogenesis: its clinical significance in human colon cancer. Gastroenterology 122: 376-386
Hashida H, Takabayashi A, Tokuhara T, Taki T, Kondo K, Kohno N, Yamaoka Y, Miyake M (2002b) Integrin $\alpha 3$ expression as a prognostic factor in colon cancer: association with MRP-1/CD9 and KAI1/CD82. Int J Cancer 97: 518-525

Health and Welfare Statistics Association (eds) (1998) Vital statistics Japan. In Journal of Health and Welfare Statistics, pp 27-40. Ministry of health and welfare, Tokyo, Japan

Hemler ME, Mannion BA, Berditchevski F (1996) Association of TM4SF proteins with integrins: relevance to cancer. Biochem Biophys Acta 1287: $67-71$

Higashiyama M, Taki T, Ieki Y, Adachi M, Huang C, Koh T, Kodama K, Doi O, Miyake M (1995) Negative motility related protein-1 (MRP-1/CD9) gene expression as a factor of poor prognosis in non-small cell lung cancer. Cancer Res 55: 6040-6044

Huang C, Kohno N, Ogawa E, Adachi M, Taki T, Miyake M (1998) Correlation of reduction in MRP-1/CD9 and KAI1/CD82 expression with recurrences in breast cancer patients. Am J Pathol 153: $973-983$

Ikeyama S, Koyama M, Yamaoka M, Sasada R, Miyake M (1993) Suppression of cell motility and metastasis by transfection with human motility-related protein (MRP-1/CD9) DNA. J Exp Med 177: 1231 - 1237

Kaplan EL, Meier P (1958) Nonparametric estimation from incomplete observations. J Am Stat Assoc 53: 457-481

Kohno M, Hasegawa H, Miyake M, Yamamoto T, Fujita S (2002) CD151 enhances cell motility and metastasis of cancer cells in the presence of focal adhesion kinase. Int J Cancer 97: 336-343

Le Naour F, Rubinstein E, Jasmin C, Prenant M, Boucheix C (2000) Severely negative female fertility in CD9-deficient mice. Science 287: $319-321$

Mantel N (1966) Evaluation of survival data and two new rank order statistics arising in its consideration. Cancer Chemother Rep 50: $163-170$

Miyake M, Hakomori S (1991) A specific cell surface glycoconjugate controlling cell motility: evidence by functional monoclonal antibodies that inhibit cell motility and tumor cell metastasis. Biochemistry 30: $3328-3334$

Miyake M, Koyama M, Seno M, Ikeyama S (1991) Identification of the motility-related protein (MRP-1), recognized by monoclonal antibody M31-15, which inhibits cell motility. J Exp Med 174: $1347-1354$

Miyake M, Nakano K, Itoi S, Koh T, Taki T (1996) Motility-related protein1 (MRP-1/CD9) reduction as a factor of poor prognosis in breast cancer. Cancer Res 56: $1244-1249$

Ono M, Honda K, Wither DA, Hakomori S (1999) Motility inhibition and apoptosis are induced by metastasis-suppressing gene product CD82 and its analogue CD9, with concurrent glycosylation. Cancer Res 59: $2335-$ 2339 
Onuma Y, Nishinakamura R, Takahashi S, Yokota T, Asashima M (1999) Molecular cloning of a novel Xenopus spalt gene (Xsal-3), Biochem Biophys Res, Comm 264: $151-156$

Rae FK, Stephenson S, Nicol DL, Clements JA (2000) Novel association of a diverse range of genes with renal cell carcinoma as identified by differential display. Int J Cancer 88: 726-732

Sho M, Adachi M, Taki T, Hashida H, Konishi T, Huang C, Ikeda N, Nakajima Y, Kanehiro H, Hisanaga M, Nakano H, Miyake M (1998) Transmembrane 4 superfamily as a prognostic factor in pancreatic cancer. Int J Cancer 79: 509-516

Sobin LH, Wittekind C (eds) (1997) TNM classification of Malignant Tumors, 5th edn. pp 66-69. New York: Wiley-Liss

Takaoka A, Hinoda Y, Satoh S, Adachi Y, Itoh F, Adachi M, Imai K (1998) Suppression of invasive properties of colon cancer cells by a metastasis suppressor KAI1 gene. Oncogene 16: $1443-1453$
Testa JE, Brooks PC, Lin J-M, Quigley JP (1999) Eukaryotic expression cloning with an antimetastatic monoclonal antibody identifies a tetraspanin (PETA-3/CD151) as an effector of human tumor cell migration and metastasis. Cancer Res 59: $3812-3820$

Tokuhara T, Hasegawa H, Hattori N, Ishida H, Taki T, Tachibana S, Sasaki S, Miyake M (2001) Clinical significance of CD151 gene expression in non-small cell lung cancer. Clin Cancer Res 7: 4109-4114

Wright MD, Tomlinson MG (1994) The ins and outs of the transmembrane 4 superfamily. Immunol Today 15: $588-594$

Yauch RL, Berditchevski F, Harler MB, Reichner J, Hemler ME (1998) Highly stoichiometric, stable, and specific association of integrin $\alpha 3 \beta 1$ with CD151 provides a major link to phosphatidylinositol 4-kinase, and may regulate cell migration . Mol Biol Cell 9: $2751-2765$ 